\title{
AKT inhibition is associated with chemosensitisation in the pancreatic cancer cell line MIA-PaCa-2
}

\author{
BN Fahy', M Schlieman', S Virudachalam' and RJ Bold*,I \\ 'Department of Surgical Oncology, University of California Davis Cancer Center, Sacramento, CA, USA
}

Activation of the serine/threonine kinase AKT is common in pancreatic cancer; inhibition of which sensitises cells to the apoptotic effect of chemotherapy. Of the various downstream targets of AKT, we examined activation of the NF- $\kappa$ B transcription factor and subsequent transcriptional regulation of BCL-2 gene family in pancreatic cancer cells. Inhibition of either phosphatidylinositol-3 kinase or AKT led to a decreased protein level of the antiapoptotic gene BCL-2 and an increased protein level of the proapoptotic gene BAX. Furthermore, inhibition of AKT decreased the function of NF- $\kappa$ B, which is capable of transcriptional regulation of the BCL-2 gene. Inhibiting this pathway had little effect on the basal level of apoptosis in pancreatic cancer cells, but increased the apoptotic effect of chemotherapy. The antiapoptotic effect of AKT activation in pancreatic cancer cells may involve transcriptional induction of a profile of BCL-2 proteins that confer resistance to apoptosis; alteration of this balance allows sensitisation to the apoptotic effect of chemotherapy.

British Journal of Cancer (2003) 89, 39I-397. doi:I0.1038/sj.bjc.660 I037 www.bjcancer.com

(c) 2003 Cancer Research UK

Keywords: AKT; BCL-2; NF- $\kappa$ B; pancreas cancer

Pancreatic cancer is a highly lethal malignancy resistant to the apoptosis-inducing effects of radio- and chemotherapy (Heinemann, 2002). Recent reports have demonstrated that the phosphatidylinositol-3 kinase (PI3K)/AKT pathway is a potent survival signal that may mediate resistance to the apoptotic effects of chemotherapy and radiation therapy in a variety of cancer types (Kandel and Hay, 1999; Brazil and Hemmings, 2001; Cantrell, 2001). Recent reports have suggested that AKT, a target of PI3K, is phosphorylated and thus activated under basal conditions in a variety of pancreatic cancer cell lines (Xue et al, 2000; Bondar et al, 2002; Samatar et al, 2002). The mechanism of AKT activation in pancreatic cancer remains unknown, although the majority of cell lines examined to date harbour constitutively activated AKT. Inhibition of PI3K, the upstream activator of AKT, has been shown to sensitise various pancreatic cancer cell lines to the apoptotic effect of chemotherapy in vitro ( $\mathrm{Ng}$ et al, 2000; Perugini et al, 2000; Yao et al, 2002). Furthermore, using these cell lines in animal studies, inhibition of PI3K was well tolerated and increased the efficacy of chemotherapy in vivo ( $\mathrm{Ng}$ et al, 2000; Bondar et al, 2002).

The downstream targets of AKT include regulators of apoptosis (BAD, caspase-9), glucose metabolism (glycogen kinase), various transcription factors (CREB and the forkhead family of transcription factors), and finally the I-kappaB kinases (IKKs). It remains unclear, however, which of these targets is involved in the antiapoptotic effect of AKT activation. The NF- $\kappa \mathrm{B}$ transcription

\footnotetext{
* Correspondence: Dr R Bold, Division of Surgical Oncology, Suite 30 I0, UC Davis Cancer Center, 450I X Street, Sacramento, CA 95817, USA; E-mail: richard.bold@ucdmc.ucdavis.edu

Received 4 February 2003; revised 24 April 2003; accepted 27 April 2003
}

factor appears to be involved in the apoptotic resistance of pancreatic cancer. This is based on observations of constitutive activation of NF- $\kappa \mathrm{B}$ in pancreatic cancer cells (Wang W et al, 1999 ) as well as the fact that inhibition of NF- $\kappa \mathrm{B}$ decreases cell survival (Shah et al, 2001) and enhances the apoptotic effect of chemotherapy in pancreatic cancer cells (Arlt et al, 2001).

$\mathrm{NF}-\kappa \mathrm{B}$ transcription factors can regulate the expression of over 100 different genes dependent on the various functional forms of NF- $\kappa \mathrm{B}$, the stimulus of NF- $\kappa \mathrm{B}$ activation and cell type examined. NF- $\kappa \mathrm{B}$ has been shown to regulate transcriptionally the expression of several members of the BCL-2 gene family, including BCL-X $\mathrm{X}_{\mathrm{L}}$ (Chen et al, 2000) and $\mathrm{A} 1$ (Wang CY et al, 1999). BCL-2 remains the prototypic antiapoptotic protein and the data are less clear as to whether NF- $\kappa \mathrm{B}$ regulates its transcription. There are reports of activation or inhibition as well as reports demonstrating no NF- $\kappa \mathrm{B}$-dependent transcriptional effect in the BCL-2 promoter (Sohur et al, 1999; Catz and Johnson, 2001; Potoka et al, 2002). In pancreatic cancer, BCL-2 is frequently overexpressed and its overexpression confers chemo- and radioresistance and enhances tumorigenic and metastatic capability (Bold et al, 1999a,b; Nio et al, 2001; Su et al, 2001). However, it remains uncertain as to whether AKT or NF- $\kappa \mathrm{B}$ is involved in the mechanism of BCL-2 transcriptional activation in pancreatic cancer.

Therefore, given the preliminary cellular studies that demonstrate that the inhibition of PI3K/AKT sensitises pancreatic cancer to the apoptotic effect of chemotherapy, we sought to determine the molecular events that may mediate this effect. The current study examines the hypothesis that a survival signal from AKT activation is mediated by NF- $\kappa \mathrm{B}$ and subsequent transcriptional regulation of BCL-2 gene family members; furthermore, inhibition of this pathway sensitises pancreatic cancer cells to the apoptotic effect of gemcitabine. 


\section{MATERIALS AND EXPERIMENTAL PROCEDURES}

\section{Materials}

All chemical reagents were purchased from Sigma Chemical Company (St Louis, MO, USA) unless otherwise specified. LY294002 was obtained from New England BioLabs (Beverly, MA, USA) and is a well-established inhibitor of PI3K-mediated activation of AKT (Cuenda and Alessi, 2000). Cell culture supplies and media were purchased from Becton Dickinson (San Diego, CA, USA) and Gibco/BRL Life Technologies (Gaithersburg, MD, USA), respectively. Plasmids for transfection experiments were purified using Qiagen's maxi kit (Valencia, CA, USA). The antibodies used included monoclonal antibodies to BCL-2, BAX, BAK, BCL- $\mathrm{X}_{\mathrm{L}}$ and MCL-1 (BD Pharmingen, San Diego, CA, USA), a polyclonal antibody to phospho-AKT (serine-473) (Biosource International Inc., Camarillo, CA, USA), polyclonal antibody to AKT (Cell Signalling Technology, Inc., Beverly, MA, USA), a polyclonal antibody to actin (Santa Cruz Biotechnology, Inc., Santa Cruz, CA, USA) and a monoclonal antibody to the p50 subunit of NF- $\kappa$ B (Oncogene Research Products, Boston, MA, USA). The luciferase assay kit was purchased from Promega Corp. (Madison, WI, USA). The dominant-negative PI3K and AKT constructs were kindly provided by Dr Hsing-Jien Kung (UC Davis). These constructs have been developed to inhibit specifically the enzymatic activity of PI3K and AKT and are used as molecular inhibitors of these signalling cascade intermediaries (Aoki et al, 1998; Osada et al, 1999).

\section{Cell culture}

The human pancreatic adenocarcinoma cell lines MIA-PaCa-2 and PANC-1 were obtained from the American Type Culture Collection (Rockville, MD, USA). The MIA-PaCa-2 cell line has been previously demonstrated to harbour constitutively activated AKT (Samatar et al, 2002). Cells were cultured in Dulbecco's modified Eagle's medium supplemented with $10 \%$ fetal calf serum, sodium pyruvate, nonessential amino acids, L-glutamine and penicillin/ streptomycin antibiotics. The cells were maintained in a humidified incubator containing $10 \% \mathrm{CO}_{2}$ at $37^{\circ} \mathrm{C}$. The cells underwent serum starvation for the $24 \mathrm{~h}$ prior to treatment with LY294002 or transient transfection.

\section{Western blotting}

Following various treatments, cells were harvested by trypsinisation (trypsin $0.25 \% \mathrm{w} \mathrm{v}^{-1}, 1 \mathrm{~mm}$ ethylenediaminetetraacetic acid). The cells were lysed in a lysis buffer containing $150 \mathrm{~mm} \mathrm{NaCl}, 1 \%$ Triton X-100 and $25 \mathrm{~mm}$ Tris (pH 7.5). Debris was sedimented by centrifugation for $5 \mathrm{~min}$ at $12000 \mathrm{~g}$, and the supernatants were solubilised for $5 \mathrm{~min}$ at $100^{\circ} \mathrm{C}$ in Laemmli's sodium dodecyl sulphate - polyacrylamide gel electrophoresis (SDS - PAGE) sample buffer containing $100 \mathrm{~mm}$ dithiothreitol. Protein concentrations of the lysates were determined with a protein quantitation kit (BioRad Laboratories, Hercules, CA, USA), and $50 \mu \mathrm{g}$ of each sample was separated on a $10 \%$ SDS - PAGE gel. Separated polypeptides were then electrophoretically transferred to $0.2-\mathrm{mm}$ nitrocellulose membranes (Schleicher \& Schuell, Keene, NH, USA). Membranes were blocked for $1 \mathrm{~h}$ in a Tris-buffered saline-Tween $(25 \mathrm{~mm}$ Tris, $\mathrm{pH} 8.0,150 \mathrm{~mm} \mathrm{NaCl}$, and $0.05 \%$ Tween-20) containing $5 \%\left(\mathrm{w} \mathrm{v}^{-1}\right)$ nonfat dried milk. The blots were then probed overnight with primary antibodies and developed using species-specific secondary and tertiary antisera. Immunoreactive material was detected by the enhanced chemiluminescence technique (Amersham).

\section{BCL-2 and NF- $\kappa$ B promoter activity}

Transcriptional regulation of the BCL-2 gene was determined using a BCL-2 promoter/luciferase construct. A $3.7 \mathrm{~kb}$ fragment of the $5^{\prime}$ untranslated region just upstream of the ATG initiation codon of BCL-2 (Miyashita et al, 1994) was generously provided by Dr Toshiyuki Miyashita (National Children's Medical Research Center, Tokyo, Japan). This fragment of the BCL-2 promoter was cloned into the pGL3-basic luciferase reporter plasmid (Promega Corp.). The NF- $\kappa \mathrm{B}$ luciferase plasmid contains four tandem copies of the NF- $\kappa \mathrm{B}$ consensus sequence fused to a TATA-like promoter (Clontech, Palo Alto, CA, USA). BCL-2 promoter activity was normalised to the activity of the control Renilla luciferase reporter, pRL-TK (Promega Corp.). Following $6 \mathrm{~h}$ of pretreatment with the various inhibitors, the promoter/luciferase reporter plasmids, BCL-2 or NF- $\kappa \mathrm{B}(2.5 \mu \mathrm{g})$, plus the control promoter/reporter, pRL-TK $(0.25 \mu \mathrm{g})$ were transiently transfected in MIA-PaCa-2 cells using lipofectin reagent (Life Technologies, Inc.). Fresh medium was applied after the cells had been in the transfection reagent for $8-12 \mathrm{~h}$. The cells were harvested $24-48 \mathrm{~h}$ after transfection by gentle scraping and resuspended in luciferase lysis buffer.

Dual luciferase assays were performed according to the manufacturer's protocol (Promega Corp.). A volume of $20 \mu \mathrm{l}$ of sample supernatant was mixed with $100 \mu$ l Luciferase Assay Reagent II followed by a $10 \mathrm{~s}$ reading of firefly luciferase activity using an Analytical Luminescence Laboratory Luminometer (Monolight 2010) followed by the addition of $100 \mu \mathrm{l}$ of Stop and Glo reagent ${ }^{\mathrm{TM}}$ (Promega Corp.). Dual luciferase assays were expressed as the ratio of firefly/Renilla RLUs. All experiments were performed in triplicate and repeated on at least three separate occasions; representative data from a single experiment are shown.

Site-directed mutagenesis of putative NF- $\kappa B$ sites within the BCL-2 promoter Putative NF- $\kappa$ B sites within the BCL-2 promoter were identified using transcriptional element site software (Schug and Overton, 1997). A site that is homologous to the NF- $\kappa \mathrm{B}$ consensus sequence ( $5^{\prime}$ GGGTNNYYCC $\left.3^{\prime}\right)$ was altered by sitedirected mutagenesis using a commercially available kit (Promega Corp.). A mutagenic oligonucleotide was synthesised to mutate two bases in the putative NF- $\kappa \mathrm{B}$ sequence at $-736 \mathrm{nt}$ (wild type: $5^{\prime}$ GGGATTCCTGC ${ }^{\prime}$; mutant: $5^{\prime}$ GTTATTCCTGC $3^{\prime}$ ). It has been recently shown that mutation of the second guanine base in an NF$\kappa \mathrm{B}$ binding site essentially eliminates both p50/p50 and p50/p65 $\mathrm{NF}-\kappa \mathrm{B}$ binding (Udalova et al, 2002). DNA sequencing was used to confirm the site-directed mutagenesis.

Electrophoretic mobility shift assay Cell extracts were prepared using a commercially available nuclear extraction kit according to the manufacturer's protocol (Pierce, Rockford, IL, USA). Electrophoretic mobility shift assay (EMSA) was performed according to the provided protocol (Promega Corp.). In brief, a 21-mer oligonucleotide corresponding to a putative NF- $\kappa \mathrm{B}$ site in the BCL-2 promoter was radiolabelled with $\left[\gamma-{ }^{32} \mathrm{P}\right]$ ATP by a T4 kinase reaction. Nucleotides were purified by chromatography through a G-25 spin column (Roche Diagnostics Corp., Indianapolis, IN, USA) equilibrated in TE buffer. In all, $10 \mu \mathrm{g}$ of nuclear protein extract were incubated with the radiolabelled NF- $\kappa$ B oligonucleotide for $20 \mathrm{~min}$ at room temperature. Supershift experiments were performed by incubating the radiolabelled NF- $\kappa \mathrm{B}$ oligonucleotide with $1 \mu \mathrm{l}$ of p50 antibody for $1 \mathrm{~h}$ on ice prior to incubation with the nuclear protein extracts. DNA: protein complexes were separated by electrophoresis through a nondenaturing $4 \%$ polyacrylamide gel in $0.5 \times \mathrm{TBE}$ at $100 \mathrm{~V}$ for $2.5 \mathrm{~h}$. Autoradiographic films were developed following $18 \mathrm{~h}$ exposure to the gels $\left(-20^{\circ} \mathrm{C}\right)$.

Determination of apoptotic cells by FACS analysis Cell cycle analysis and quantification of apoptosis analysis was carried out as described previously using propidium iodide (PI) staining and fluorescence-activated cell sorting (FACS) (Bold et al, 1999a, b). In brief, following treatment, the cells were collected by gentle 
trypsinisation, washed in phosphate-buffered saline (PBS), and pelleted by centrifugation. The cells were fixed in $70 \%$ ethanol, washed twice in PBS and resuspended in PBS containing RNAse A $\left(20 \mu \mathrm{g} \mathrm{ml}^{-1}\right)$. The cells were stained with PI (final concentration $0.1 \mathrm{mg} \mathrm{ml}^{-1}$ ) for $10 \mathrm{~min}$ at room temperature. The samples underwent FACS analysis (FL-3 channel) using a Beckman Coulter Counter Epics XL flow cytometer (Beckman Coulter, Inc., Miami, FL, USA). For each sample, 10000 events were collected and stored for subsequent analysis using EXPO software (version 2.0; Applied Cytometry Systems, South Yorkshire, UK). Data were elaborated using Autofit feature of the Multicycle for Windows software (version 3.0, University of Washington, WA, USA) and expressed as fraction of cells in the different cycle phases. The percentage of cells in the sub- $G_{0}$ phase was quantitated as an estimate of cells undergoing apoptosis.

\section{RESULTS}

We confirmed that the MIA-PaCa-2 cell line demonstrates the activation of AKT under basal conditions by Western blotting with a phospho-specific (serine 473) antibody (Figure 1). The level of AKT activation in MIA-PaCa-2 is well below that of the human prostate cancer cell line LNCaP, which harbours a PTEN mutation and thus has high levels of PI3K activity (Davies et al, 1999). In comparison to MIA-PaCa-2, the pancreatic cancer cell line PANC-1 has very low levels of basal activation of AKT (Figure 1). The effect of PI3K/AKT inhibition on the levels of the BCL-2 gene family was determined by transiently transfecting MIA-PaCa-2 cells with dominant-negative mutants of either PI3K or AKT and performing Western blots. Both PI3K and AKT inhibition decreased BCL-2 expression and increased BAX expression without effect on MCL$1, \mathrm{BCL}-\mathrm{X}_{\mathrm{L}}$ or BAK (Figure 2).

To determine whether these changes were mediated by alterations in gene transcription, we focused our investigation on the BCL-2 gene. To eliminate any potential effect of sequential transfections, we utilised the established pharmacologic inhibitor of PI3K, LY294002. Following treatment with LY294002, a dosedependent reduction in BCL-2 promoter activity was observed only in the MIA-PaCa-2 cell line, but not in the PANC-1 cell line (Figure 3), which has a much lower level of basal AKT activation. We examined similarly the transactivational function of $\mathrm{NF}-\kappa \mathrm{B}$, given its potential regulatory function of BCL-2 gene transcription. A parallel reduction in NF- $\kappa$ B function was also observed following PI3K inhibition with LY294002 in the MIA-PaCa-2 cell line (Figure 3C).
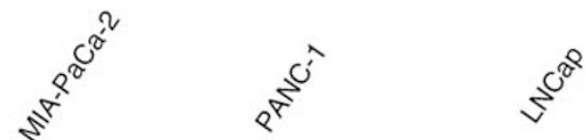

P-AKT
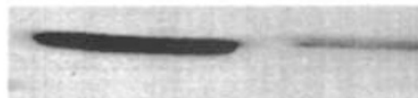

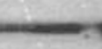

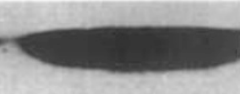

Actin

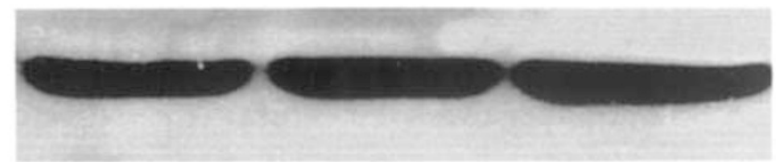

Figure I Levels of phospho-AKT (serine-473) and actin in the two human pancreatic cancer cell lines MIA-PaCa-2 and PANC-I, with the human prostate cancer cell line LNCaP as a positive control, which harbours a mutation in PTEN and thus demonstrates constitutive activation of PI3K (Davies et al, 1999).

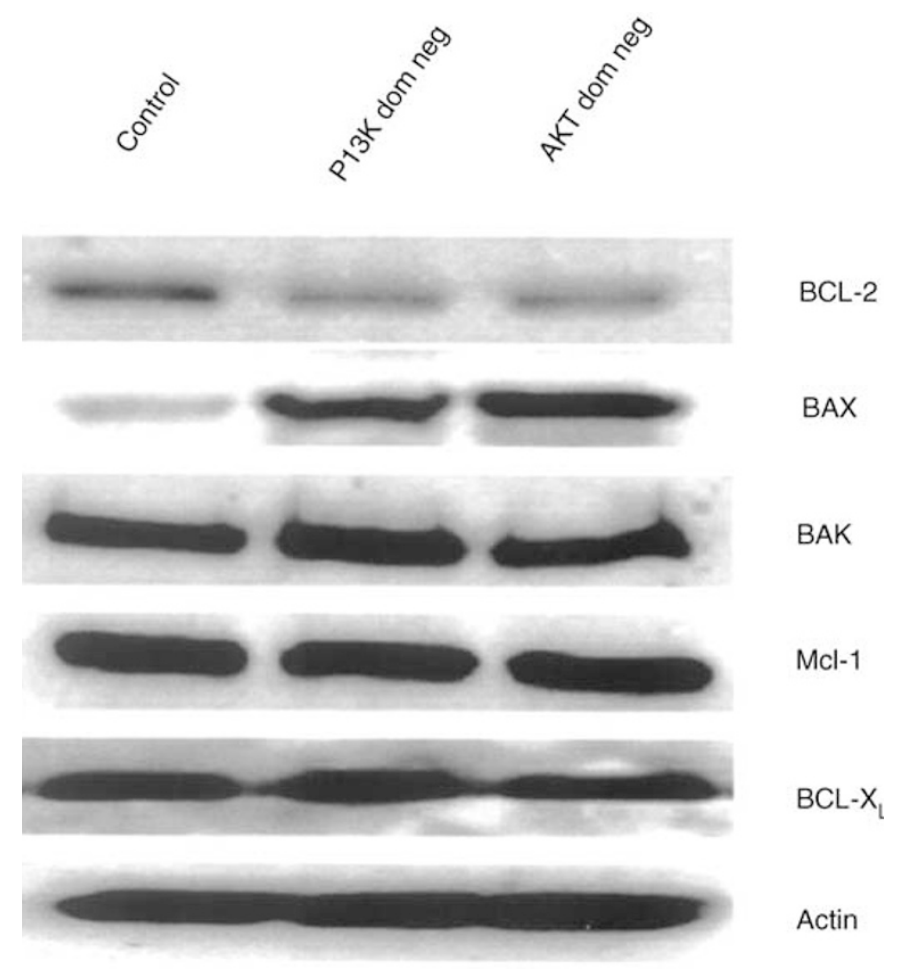

Figure 2 Effect of inhibition of PI3K or AKT (through transient transfection of the dominant-negative mutants ('dom neg') of these kinases) on $\mathrm{BCL}-2$ family protein expression. Actin is shown for equivalency of loading.

This decrease in the content of an antiapoptotic protein (BCL-2) with an increase in the level of a proapoptotic protein (BAX) is a pattern consistent with a lower threshold for the induction of apoptosis. We determined whether these cells would undergo spontaneous apoptosis following PI3K inhibition alone. Using flow cytometry, we observed little change in the induction of apoptosis following treatment with a wide range of doses of LY294002 (Figure 4). These cells exhibit a low level of spontaneous apoptosis, which was unchanged following treatment with any dose of LY294002. Of note, these doses were sufficient to decrease dramatically BCL-2 transcription as seen above, as well as protein levels (data not shown).

Having shown that the inhibition of AKT activation by PI3K reduces NF- $\kappa$ B activity, BCL-2 promoter activity and subsequent protein expression, we next sought to more definitively establish the link between NF- $\kappa \mathrm{B}$ and BCL-2. To do this, a putative NF- $\kappa \mathrm{B}$ site within the BCL-2 promoter underwent site-directed mutagenesis in which two bases were mutated. BCL-2 promoter activity reduced by $77 \%$ following site-directed mutation of the putative $\mathrm{NF}-\kappa \mathrm{B}$ site (Figure 5). The effect of mutating this NF- $\kappa \mathrm{B}$ site in conjunction with PI3K inhibition on BCL-2 promoter activity was also examined. No further decrease in BCL-2 promoter activity was seen when PI3K inhibition was combined with mutation of the NF$\kappa \mathrm{B}$ site (Figure 5). These data indicate that NF- $\kappa \mathrm{B}$ is the dominant transcription factor activated by PI3K in the regulation of BCL-2 promoter function, and that the site at $-736 \mathrm{nt}$ is the major NF- $\kappa \mathrm{B}$ site.

Final confirmation of the role of NF- $\kappa \mathrm{B}$ as mediator of the effect of PI3K on BCL-2 was achieved by EMSA. Using a radiolabelled 18-base oligonucleotide corresponding to the putative NF- $\kappa \mathrm{B}$ site in the BCL-2 promoter $(-736 \mathrm{nt})$, the typical pattern of $\mathrm{p} 50$ / p65 and p50/50 bands are observed (Figure 6, lane 2). These bands were competed away by an excess of unlabelled NF- $\kappa \mathrm{B}$ 
A

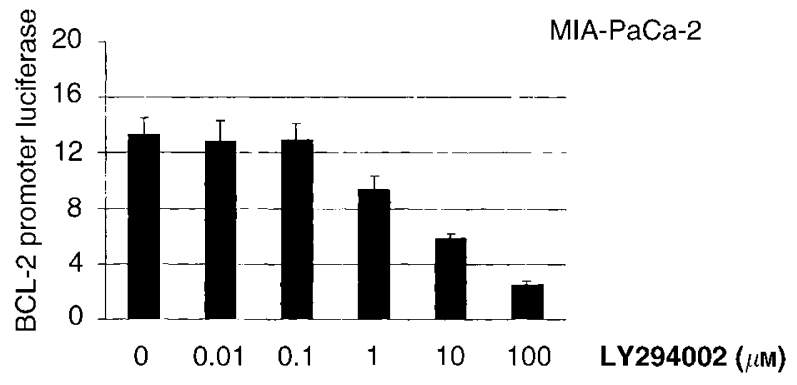

B

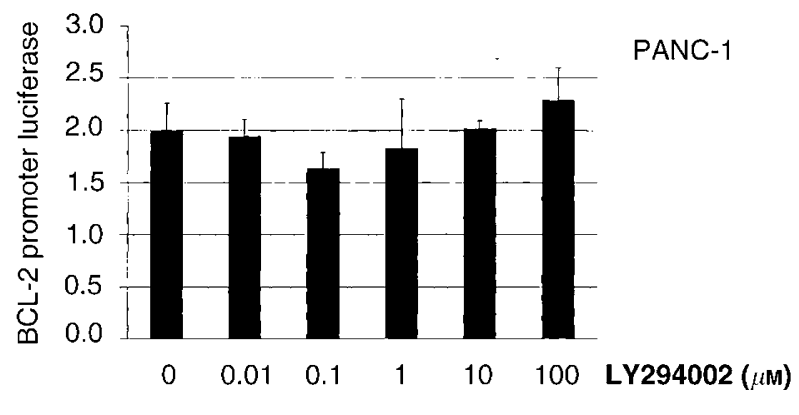

C

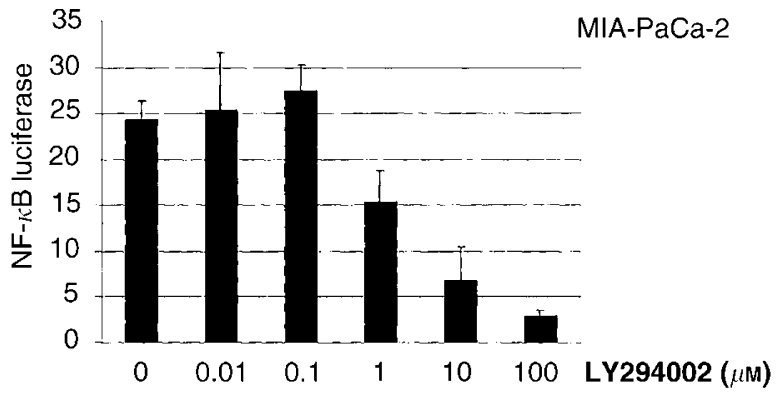

Figure 3 Treatment with the PI3K inhibitor, LY294002 inhibited the activation BCL-2 promoter in the MIA-PaCa-2 cell line in a dose-dependent manner(A) but without effect in the PANC-I cell line (B). Furthermore, LY294002 inhibited NF- $\kappa$ B transcriptional activity in MIA-PaCa-2 cells (C) Total lysate firefly luciferase was normalised to Renilla luciferase following dual transfection.

oligonucleotide (lane 3 ), but not by either oligonucleotides representing the mutant NF- $\kappa \mathrm{B}$ sequence from the site-directed mutagenesis (lane 4) or an AP-1 consensus oligonucleotide (lane 5 ). The identity of the transcriptional element was confirmed by adding the antibody to the $\mathrm{p} 50$ subunit of NF- $\kappa \mathrm{B}$ to demonstrate a supershifted complex (lane 6). Finally, the effect of PI3K inhibition on this NF- $\kappa \mathrm{B}$ binding to the -736 nt site in the BCL-2 promoter was examined by treating the cells with LY294004 for $5 \mathrm{~h}$ prior to nuclear protein harvest. Of specific interest is the elimination of the upper p50/p65 complex only, with accentuation of the lower p50/p50 complex. This suggests that the NF- $\kappa \mathrm{B}$ signalling mediated by PI $3 \mathrm{~K}$ is primarily through p 65 activity with little effect on p50 activity.

As we observed very little apoptosis associated with the various treatments employed to inhibit PI3K or AKT, we subsequently investigated the cellular response to the inhibition of this signalling pathway as well as to exposure to gemcitabine, a standard chemotherapy for pancreatic cancer. Using FACS analysis, we observed a small increase in the induction of apoptosis with gemcitabine (Figure 7), consistent with the literature that report little apoptotic effect of gemcitabine in these cells following shortterm treatment (Xu et al, 2001). PI3K or AKT inhibition using the dominant-negative constructs induced apoptosis to a minor degree

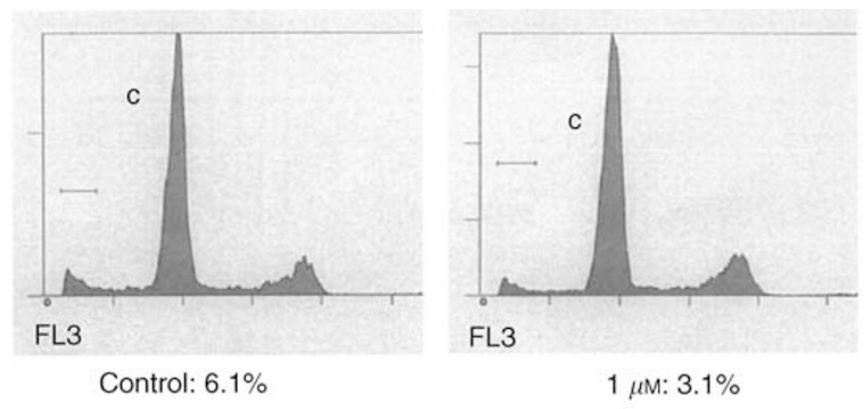

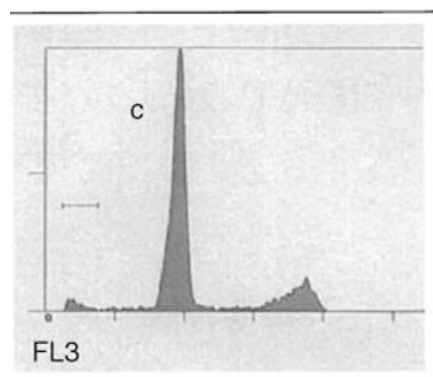

$10 \mu \mathrm{m}: 4.1 \%$

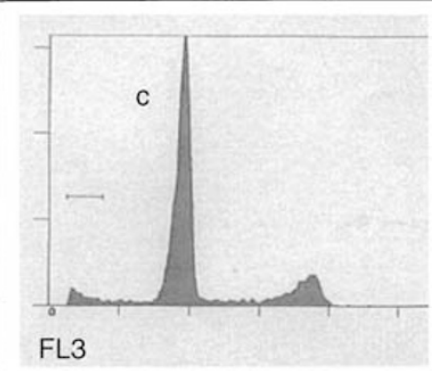

$50 \mu \mathrm{M}: 4.9 \%$
Figure 4 FACS analysis following $24 \mathrm{~h}$ of treatment with the indicated doses of the PI3K inhibitor, LY294002. Also shown is the relative percentage of cells in the sub-Go phase of cell distribution, which corresponds to the fraction undergoing apoptosis. Data is graphed by number of events on $x$-axis and logarithmic value of flourescent intensity on y-axis.

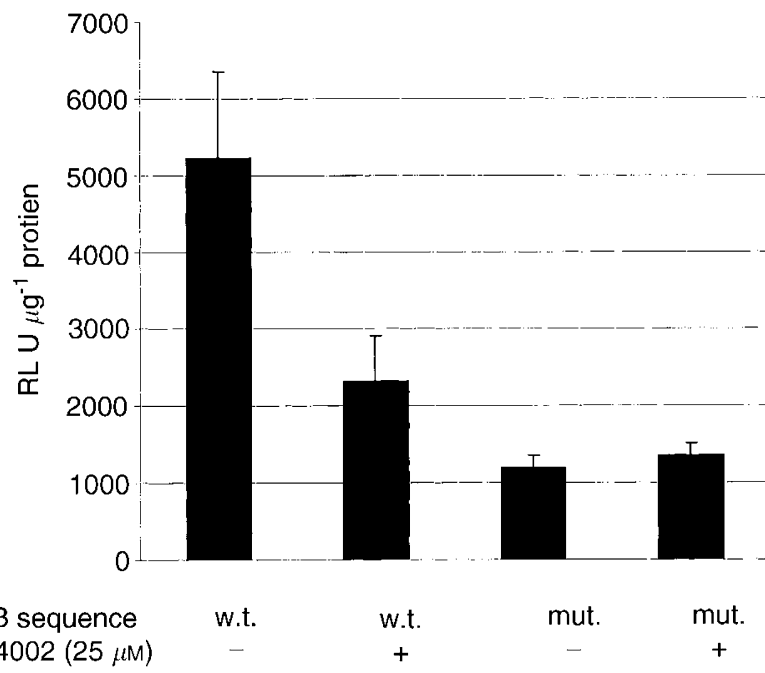

$\begin{array}{lcccc}\text { NF }-\kappa B \text { sequence } & \text { w.t. } & \text { w.t. } & \text { mut. } & \text { mut } \\ \text { LY294002 }(25 \mu \mathrm{M}) & - & + & - & +\end{array}$

Figure 5 Effect of mutation of the $N F-\kappa B$ site on $B C L-2$ promoter activity was examined using a full-length $\mathrm{BCL}-2$ promoter/luciferase reporter containing a site-specific mutation ('mut.') compared to the wild-type BCL-2 promoter ('w.t.') in the absence or presence of LY294002. Total lysate RLUs were normalised for protein concentration of the cellular lysate for equivalency of analysis.

(Figure 7). However, there was a significant increase when the cells were treated with gemcitabine in the presence of PI3K or AKT inhibition (Figure 7). Therefore, the addition of PI3K or AKT inhibition converts gemcitabine into a potent apoptotic agent.

\section{DISCUSSION}

Inhibition of the PI3K/AKT pathway has repeatedly and consistently been shown to sensitise pancreatic cancer cells in vitro and 

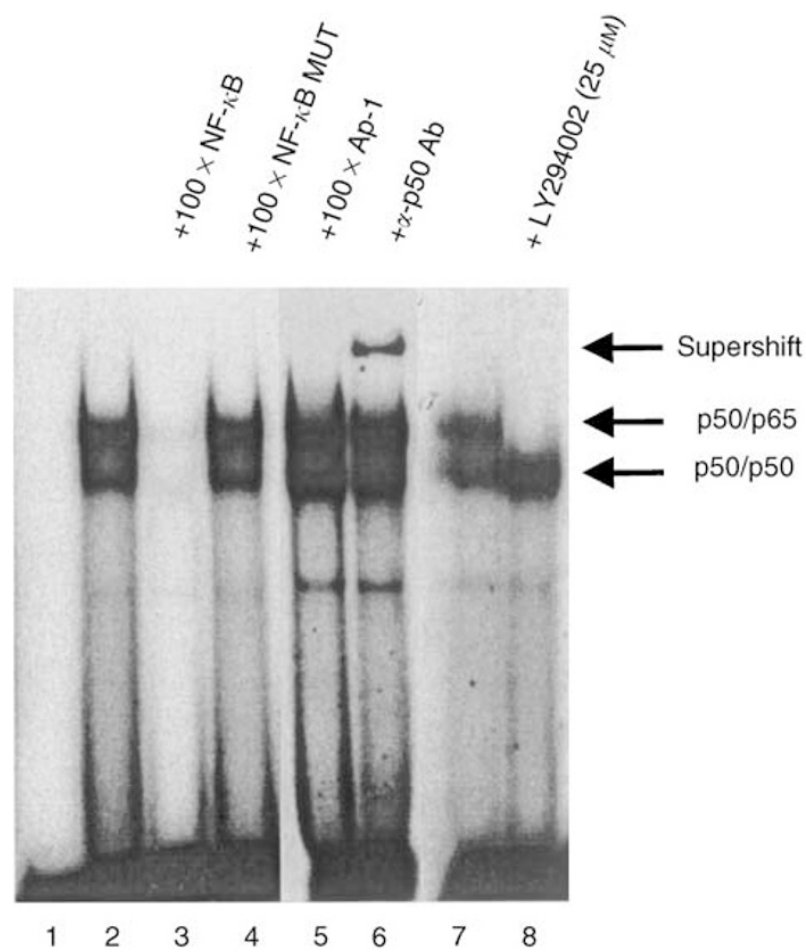

Figure 6 Examination of the NF- $\kappa B$ site at $-736 \mathrm{nt}$ within the $B C L-2$ promoter by EMSA. MIA-PaCa-2 nuclear lysate was incubated with radiolabelled oligonucleotides corresponding to the NF- $\kappa$ B site (except lane I) and underwent cold competition ( $100 \times$ molar excess) of nucleotides corresponding to the NF- $\kappa \mathrm{B}$ site (lane 3 ), the site-directed mutant of the NF- $\kappa$ B site (lane 4), or an unrelated transcriptional site, AP- I (lane 5). Supershift of the NF- $\kappa \mathrm{B}$ complex was achieved using an antibody to the p50 subunit of NF- $\kappa \mathrm{B}$ (lane 6). Treatment of the cells with LY294002 eliminated the upper p50/p65 band of the typical NF- $\kappa$ B gelshift pattern (lane 8).

in vivo to the apoptotic effect of chemotherapy. The mechanism by which AKT activation in these cancer cells confers chemoresistance is unclear. AKT has been shown to have multiple targets, including mediators of apoptosis (e.g. caspase-9 and BAD), transcription factors (e.g. FKHD and CREB) and assorted kinases (e.g. raf, GSK-3 and IKK). There has been extensive investigation coupling AKT to IKK and subsequent NF- $\kappa$ B activation, which can be a potent survival signal through transcription of various target genes. However, which genes confer this effect is undergoing further investigation.

The effect of modifying single members of the BCL-2 gene family on apoptotic response has been examined in a variety of cancer types and models. However, it is now accepted that while the levels of a single member of the BCL-2 gene family can be associated with apoptotic response, the overall balance of proapoptotic to antiapoptotic proteins (such as the BCL-2:BAX ratio) sets the threshold for the induction of apoptosis in response to an external stimulus (Mirjolet et al, 2000). This is likely related to the function of these proteins through their ability to homo- and heterodimerise. Homodimers of proapoptotic proteins are sufficient for the induction of apoptosis; high levels of expression of antiapoptotic BCL-2 family members saturate the proapoptotic members and prevent the initiation of the apoptotic cascade (Mikhailov et al, 2001). Cancer cells are chemoresistant by virtue of an elevated threshold for the induction of apoptosis (termed 'apopstat'). Indeed, dysregulation of BCL-2 gene family expression is common in most cancers, although the mechanisms are unclear.

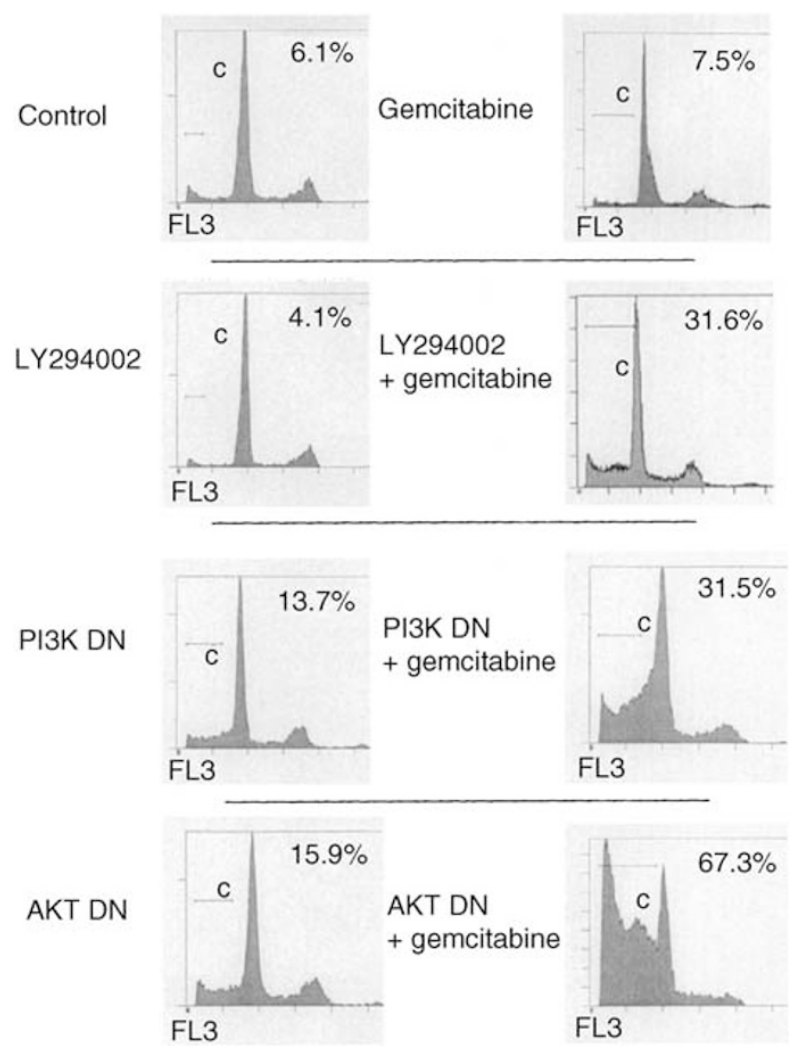

Figure 7 FACS analysis following indicated treatments of LY294002 ( $10 \mu \mathrm{M})$, transient transfection with dominant-negative (DN) mutant forms of either PI3K or AKT alone or in combination with gemcitabine (I00 $\mu \mathrm{M})$. Also shown is the relative percentage of cells in the sub-Go phase of cell distribution, which corresponds to the fraction of cells undergoing apoptosis. Data is displayed in similar format to that of Figure 4.

Unlike other genetic events associated with cancer, altered expression of BCL-2 family members appears to occur at the level of transcription. A review of the reported effect of PI3K inhibition on BCL-2 family transcription reveals diverse functions that are dependent on cell type. In the JYTF-1 haematopoietic progenitor cell line, PI3K inhibition decreased MCL-1 levels, but had no effect on BCL-2 or BAX levels (Huang et al, 2000). On the other hand, in FDCP-1 (B-cell progenitor line) or PC12 (rat pheochromocytoma) cells, PI3K inhibition decreased BCL-2 gene transcription (Minshall et al., 1999; Pugazhenthi et al, 2000). Finally, in hippocampal neurons, PI3K inhibition decreased BCL-2 and increased BAX (Matsuzaki et al, 1999). Our data show that PI3K/ AKT inhibition in these pancreatic cancer cells results in a decrease in BCL-2 and an increase in BAX without effect on other members of the BCL-2 family; furthermore, this effect appears limited to those cell lines that demonstrate AKT activation under basal conditions.

The specific mediators of BCL-2 transcription have been an active area of research. Pugazhenthi reported that the PI3Kmediated transcriptional regulation of BCL-2 was through transactivation of the CREB transcription factor (Pugazhenthi et al, 2000), although among the AKT-activated transcription factors, NF- $\kappa \mathrm{B}$ has been more consistently integrated into antiapoptotic signalling through regulation of either BCL- $\mathrm{X}_{\mathrm{L}}$ or A1/Bfl-1 (Wang W et al, 1999). Whether NF- $\kappa \mathrm{B}$ functions as a transcriptional activator or repressor of BCL-2 remains unclear. Using the FL5.12 B-cell progenitor line, NF- $\kappa \mathrm{B}$ activation repressed transcription of the BCL-2 gene (Sohur et al. 1999). Conversely, in a model of androgen withdrawal from prostate cancer cells, NF- $\kappa \mathrm{B}$ activation induced BCL-2 gene transcription (Catz and Johnson, 
2001). Heckman failed to identify a function NF- $\kappa$ B site in the BCL-2 promoter of lymphoma cells harbouring a $t(14: 18)$ translocation (Heckman et al, 2002), although the functional NF$\kappa \mathrm{B}$ site we have identified is within the promoter analysed by these investigators. It is clear from these various reports, that the integrity and function of $\mathrm{PI} 3 \mathrm{~K} / \mathrm{NF}-\kappa \mathrm{B} / \mathrm{BCL}-2$ signalling pathway is dependent on a variety of factors, including cell type, genetic background and transformed status. Of interest, we observed that PI3K inhibition did not further decrease BCL-2 promoter activity harbouring a mutated NF- $\kappa \mathrm{B}$ site, suggesting that NF- $\kappa \mathrm{B}$ alone was the major transcription factor activated by PI3K, and it functioned primarily at the $-736 \mathrm{nt}$ location.

Previous studies have demonstrated that the inhibition of PI3K sensitises pancreatic cancer to the apoptotic effect of chemotherapy; our studies provide data to define a signalling pathway that involves alterations in relative levels of BCL-2 family members. Inhibition of PI3K/AKT has minimal effect on the basal level of apoptosis, although it leads to a lower threshold for the induction of apoptosis in response to chemotherapy. These data suggest that targeted inhibition of the PI3K/AKT pathway may not be an appropriate therapy when administered alone, but may improve the efficacy of standard chemotherapeutic agents. An improved understanding of the mechanism(s) by which pancreatic cancer cells evade apoptotic signals may result in the development of novel therapies that can restore apoptotic sensitivity in this highly lethal malignancy.

\section{ACKNOWLEDGEMENTS}

This work was presented in part at the 55th Annual Cancer Symposium of the Society of Surgical Oncology (14-17 March 2002; Denver, CO, USA). This work was supported by grants to RJB from the Lustgarten Foundation (LF01-032) and the University of California Cancer Research Coordinating Commission.

\section{REFERENCES}

Aoki M, Batista O, Bellacosa A, Tsichlis P, Vogt PK (1998) The akt kinase: molecular determinants of oncogenicity. Proc Natl Acad Sci USA 95: $14950-14955$

Arlt A, Vorndamm J, Breitenbroich M, Folsch UR, Kalthoff H, Schmidt WE, Schafer H (2001) Inhibition of NF-kappaB sensitizes human pancreatic carcinoma cells to apoptosis induced by etoposide (VP16) or doxorubicin. Oncogene 20: 859-868

Bold RJ, Chandra J, McConkey DJ (1999a) Gemcitabine-induced programmed cell death (apoptosis) of human pancreatic carcinoma is determined by Bcl-2 content. Ann Surg Oncol 6: 279-285

Bold RJ, Hess KR, Pearson AS, Grau AM, Sinicrope FA, Jennings M, McConkey DJ, Bucana CD, Cleary KR, Hallin PA, Chiao PJ, Abbruzzese JL, Evans DB (1999b) Prognostic factors in resectable pancreatic cancer: p53 and bcl-2. J Gastrointest Surg 3: 263-277

Bondar VM, Sweeney-Gotsch B, Andreeff M, Mills GB, McConkey DJ (2002) Inhibition of the phosphatidylinositol $3^{\prime}$-kinase-AKT pathway induces apoptosis in pancreatic carcinoma cells in vitro and in vivo. Mol Cancer Ther 1: $989-997$

Brazil DP, Hemmings BA (2001) Ten years of protein kinase B signalling: a hard Akt to follow. Trends Biochem Sci 26: 657-664

Cantrell DA (2001) Phosphoinositide 3-kinase signaling pathways. J Cell Sci 114: $1439-1445$

Catz SD, Johnson JL (2001) Transcriptional regulation of bcl-2 by nuclear factor kappa B and its significance in prostate cancer. Oncogene 20: 7342 - 7351

Chen C, Edelstein LC, Gelinas C (2000) The Rel/NF-kappaB family directly activates expression of the apoptosis inhibitor Bcl-x(L). Mol Cell Biol 20: $2687-2695$

Cuenda A, Alessi DR (2000) Use of kinase inhibitors to dissect signaling pathways. Methods Mol Biol 99: 161-175

Davies MA, Koul D, Dhesi H, Berman R, McDonnell TJ, McConkey D, Yung WK, Steck PA (1999) Regulation of Akt/PKB activity, cellular growth, and apoptosis in prostate carcinoma cells by MMAC/PTEN. Cancer Res 59: $2551-2556$

Heckman CA, Mehew JW, Boxer LM (2002) NF-kappaB activates Bcl-2 expression in $\mathrm{t}(14 ; 18)$ lymphoma cells. Oncogene 21: $3898-3908$

Heinemann V (2002) Present and future treatment of pancreatic cancer Semin Oncol 29(3 Suppl 9): 23-31

Huang H-M, Huang C-J, Yen JJ-Y (2000) Mcl-1 is a common target of stem cell factor and interleukin-5 for apoptosis prevention activity via MEK/ MAPK and PI-3K/Akt pathways. Blood 96: $1764-1771$

Kandel ES, Hay N (1999) The regulation and activities of the multifunctional serine/threonine kinase Akt/PKB. Exp Cell Res 253: $210-229$

Matsuzaki H, Tamatani M, Mitsuda N, Namikawa K, Kiyama H, Miyake S, Tohyama M (1999) Activation of Akt kinase inhibits apoptosis and changes in Bcl-2 and Bax expression induced by nitric oxide in primary hippocampal neurons. J Neurochem 73: $2037-2046$

Mikhailov V, Mikhailova M, Pulkrabek DJ, Dong Z, Venkatachalam MA, Saikumar P (2001) Bcl-2 prevents Bax oligomerization in the mitochondrial outer membrane. J Biol Chem 276: $18361-18374$

Minshall C, Arkins S, Dantzer R, Freund GG, Kelley KW (1999) Phosphatidylinositol $3^{\prime}$-kinase, but not S6-kinase, is required for

insulin-like growth maintain expression of $\mathrm{Bcl}-2$ and promote survival of myeloid progenitors. J Immunol 162: $4542-4549$

Mirjolet JF, Barberi-Heyob M, Didelot C, Peyrat JP, Abecassis J, Millon R, Merlin JL (2000) Bcl-2/Bax protein ratio predicts 5-fluorouracil sensitivity independently of p53 status. Br J Cancer 83: $1380-1386$

Miyashita T, Harigai M, Hanada M, Reed JC (1994) Identification of a p53dependent negative response element in the bcl-2 gene. Cancer Res 54: $3131-3135$

Ng SSW, Tsao MS, Chow S, Hedley DW (2000) Inhibition of phosphatidylinositide 3-kinase enhances gemcitabine-induced apoptosis in human pancreatic cancer cells. Cancer Res 60: $5451-5455$

Nio $\mathrm{Y}$, Dong $\mathrm{M}$, Iguchi $\mathrm{C}$, Yamasawa $\mathrm{K}$, Toga $\mathrm{T}$, Itakura $\mathrm{M}$, Tamura $\mathrm{K}$ (2001) Apoptosis and expression of Bcl-2 and Bax proteins in invasive ductal carcinoma of the pancreas. J Surg Oncol 76: 188-196

Osada M, Tolkacheva T, Li W, Chan TO, Tsichlis PN, Saez R, Kimmelman AC, Chan AM (1999) Differential roles of Akt, Rac, and Ral in R-Rasmediated cellular transformation, adhesion, and survival. Mol Cell Biol 119: $6333-6344$

Perugini RA, McDade TP, Vittimberga FJ, Callery MP (2000) Pancreatic cancer cell proliferation is phosphatidylinositol 3-kinase dependent. J Surg Res 90: 39-44

Potoka DA, Upperman JS, Nadler EP, Wong CT, Zhou X, Zhang XR, Ford HR (2002) NF-kappaB inhibition enhances peroxynitrite-induced enterocyte apoptosis. J Surg Res 106: 7-14

Pugazhenthi S, Nesterova A, Sable C, Heidenreich KA, Boxer LM, Heasley LE, Reusch JE (2000) Akt/protein kinase B up-regulates Bcl-2 expression through cAMP-response element-binding protein. J Biol Chem 275: $10761-10766$

Samatar AA, Wang L, Mirza A, Koseoglu S, Liu S, Kumar CC (2002) Transforming growth factor-beta 2 is a transcriptional target for Akt/ protein kinase B via forkhead transcription factor. J Biol Chem 277: $28118-28126$

Schug J, Overton GC (1997) Technical Report CBIL-TR-1997-1001-v0.0. The Computational Biology and Informatics Laboratory, School of Medicine, University of Pennsylvania

Shah SA, Potter MW, McDade TP, Ricciardi R, Perugini RA, Elliott PJ Adams J, Callery MP (2001) 26S proteasome inhibition induces apoptosis and limits growth of human pancreatic cancer. J Cell Biochem 82: $110-122$

Sohur US, Dixit MN, Chen CL, Byrom MW, Kerr LA (1999) Rel/NF-kappaB represses bcl-2 transcription in pro-B lymphocytes. Gene Expr 8: 219-229

Su Z, Lebedeva IV, Gopalkrishnan RV, Goldstein NI, Stein CA, Reed JC Dent P, Fisher PB (2001) A combinatorial approach for selectively inducing programmed cell death in human pancreatic cancer cells. Proc Natl Acad Sci USA 98: $10332-10337$

Udalova IA, Mott R, Field D, Kwiatkowski D (2002) Quantitative prediction of NF- $\kappa \mathrm{B}$ DNA-protein interactions. Proc Natl Acad Sci USA 99: $8167-8172$

Wang CY, Guttridge DC, Mayo MW, Baldwin Jr AS (1999) NF-kappaB induces expression of the $\mathrm{Bcl}-2$ homologue $\mathrm{A} 1 / \mathrm{Bfl}-1$ to preferentially suppress chemotherapy-induced apoptosis. Mol Cell Biol 19: 5923-5929 
Wang W, Abbruzzese JL, Evans DB, Larry L, Cleary KR, Chiao PJ (1999) The nuclear factor-kappa B RelA transcription factor is constitutively activated in human pancreatic adenocarcinoma cells. Clin Cancer Res 5: $119-127$

Xu Z, Friess H, Solioz M, Aebi S, Korc M, Kleeff J, Buchler MW (2001) Bcl$\mathrm{x}(\mathrm{L})$ antisense oligonucleotides induce apoptosis and increase sensitivity of pancreatic cancer cells to gemcitabine. Int J Cancer 94: 268-274
Xue L, Murray JH, Tolkovsky AM (2000) The ras/phosphatidylinositol 3kinase and ras/ERK pathways function as independent survival modules each of which inhibits a distinct apoptotic signaling pathway in sympathetic neurons. J Biol Chem 275: 8817-8824

Yao Z, Okabayashi Y, Yutsudo Y, Kitamura T, Ogawa W, Kasuga M (2002) Role of Akt in growth and survival of PANC-1 pancreatic cancer cells. Pancreas 24: $42-43$ 